\title{
HISTÓRIA \\ Apresentação ao dossiê "Futebol, biografias e memórias"
}

Bernardo Buarque de Hollanda

Raphael Rajão Ribeiro

\section{APRESENTAÇÃO AO DOSSIÊ "FUTEBOL, BIOGRAFIAS E MEMÓRIAS”}

\author{
Bernardo Buarque de Hollanda \\ Professor da Escola de Ciências Sociais (FGV-CPDOC) \\ Raphael Rajão Ribeiro \\ Doutorando em História Política e Bens Culturais (FGV-CPDOC)
}

O período que vai de 2007 a 2016 foi cognominado, em coletânea recente, de "a década esportiva" (Spaggiari; Machado; Giglio, 2016). O balizamento temporal desses dez anos faz alusão, por suposto, ao intervalo que se estende entre o anúncio da Copa do Mundo no Brasil pela FIFA e a realização dos Jogos Olímpicos de verão na cidade do Rio de Janeiro, ocorridos há três anos atrás.

No referido decênio, como sabemos, o país assistiu a uma série de convulsões político-sociais. O otimismo, o crescimento, a inclusão e as promessas até então reinantes, e que incluíam os megaeventos esportivos na agenda das transformações e promoções por que passava a nação, parecem ter sido levados de roldão pela onda conservadora e pelo abalo institucional vivenciado em tal conjuntura histórica, a se arrastar até os dias de hoje.

Não cabe aqui, nos limites dessa apresentação, discorrermos sobre esse ponto, mas talvez valha a pena pinçar desse quadro de múltiplas, sucessivas e desencontradas crises das instituições de poder ao menos um aspecto que pode ser considerado positivo. Dentro daquilo que nos compete, tal aspecto diz respeito ao contexto dos grandes eventos de esportes transcorridos no país, com especial atenção ao futebol.

O estudo de Campos (et. al., 2017), dedicado a mapear a presença do futebol nas Ciências Sociais e Humanas no decorrer do século XXI, traz um levantamento que pode ser tomado como alvissareiro para a consolidação desse subcampo disciplinar no país. A despeito da persistência das disparidades regionais, apontadas criticamente pela equipe de pesquisa associada ao GEFuT - Grupo de Estudos em Futebol e Torcidas, da Escola de Educação Física/UFMG -, a investigação mostrou 


\section{HISTÓRIA \\ Apresentação ao dossiê "Futebol, biografias e memórias"}

Bernardo Buarque de Hollanda

Raphael Rajão Ribeiro

um incremento quantitativo notável na produção científica com temática futebolística nos últimos anos.

Talvez seja problemático postularmos aqui os efeitos de um "legado acadêmico" - apropriação do termo nativo, supostamente beneficente, da organização promotora da segunda Copa do Mundo realizada no Brasil em 2014 -, mas é indubitável que a visibilidade do megaevento planetário estimulou a criação de grupos e projetos de pesquisa; propiciou a realização de fóruns e reuniões em associações de pósgraduação; e motivou a organização de dossiês e artigos nos periódicos científicos centrados no temário do futebol.

Se a consolidação de tais estudos vai-se mostrar duradoura, apenas os próximos anos e as futuras pesquisas de mapeamento irão dizer. De todo modo, é de se esperar que a quantidade de novos trabalhos implique em elevação de qualidade e em adensamento analítico, bem como que a curva ascendente apontada pela equipe do GEFuT reverta-se, pelo menos no médio e no longo prazo, na estabilização dessa seara de investigações.

Para as gerações que hoje começam a lidar com o objeto, trata-se de uma forma otimista de dizer que o futebol doravante não será mais "tema menor". Tampouco que o mesmo carecerá de seriedade e legitimidade no rol dos assuntos relevantes, tal como parte da Academia e do senso-comum quis, durante bom tempo, nos fazer acreditar.

Um dos sinais da afirmação e da consolidação dos estudos futebolísticos é o interesse dos pesquisadores em fase de formação na pós-graduação dos cursos de História e de Ciências Sociais em se dedicar a este assunto. Mais do que contabilizar números de dissertações e teses defendidas, um caminho possível para aferir o estado da arte é levantar os dossiês que vêm sendo organizados ultimamente nas revistas discentes de pós.

A título de exemplificação, invoquemos os volumes que resultaram em publicações no ano de 2018. Um primeiro exemplo é o da Revista Mosaico, dirigida pelos alunos do Programa de Pós-Graduação em História Política e Bens Culturais 


\section{HISTÓRIA \\ Apresentação ao dossiê "Futebol, biografias e memórias"}

Bernardo Buarque de Hollanda

Raphael Rajão Ribeiro

(CPDOC-FGV), que se intitulou "Diálogos com o futebol"1. O segundo, denominado "História dos esportes e do lazer", foi uma iniciativa da Revista discente Hydra, vinculada à pós-graduação em História da Universidade Federal de São Paulo/UNIFESP ${ }^{2}$.

O presente dossiê, cuja chamada foi lançada no ano passado, vem ao encontro dessa tendência que consideramos positiva e sintomática do interesse de mestrandos e doutorandos pela abordagem acadêmica do futebol. Pertencente ao Programa de Pós-graduação em História da Universidade Federal da Grande Dourados (UFGD), sediado no estado de Mato Grosso do Sul, o periódico eletrônico discente História em Reflexão, criado há mais de dez anos (2007) e publicado com regularidade semestral, também elegeu para tematização em 2019 o futebol.

Convidados pela editora da revista Kelen Katia Prates Silva, mestranda do Programa, a delinear as diretrizes do supracitado dossiê, amadurecemos inicialmente qual seria o escopo preferencial por definir. Com o critério preliminar da exclusão dos temas relativamente explorados em publicações precedentes, orientamo-nos pelo capítulo de balanço feito pela professora da UFF, Simoni Lahud Guedes, acerca da produção científica concernente ao eixo "Esporte, lazer e sociabilidade" (2010), em coletânea organizada pela Associação Nacional de Pós-Graduação em Ciências Sociais, a ANPOCS.

No tocante à antropologia do futebol, a pesquisadora destaca duas temáticas que avultaram nos últimos anos, tornando-se recorrentes, em função de sua visibilidade e de sua percepção mais abrangente como "problema social". A primeira concerne às identidades construídas por meio do futebol, com mais ênfase para a relação identitária do país com a Seleção Brasileira e com as Copas do Mundo, à luz das chamadas "comunidades imaginadas", de que falava Benedict Anderson para

\footnotetext{
${ }^{1}$ Disponível em: http://bibliotecadigital.fgv.br/ojs/index.php/mosaico/issue/view/4166.

2 Disponível em: http://www.hydra.sites.unifesp.br/index.php/pt/numeros/75-numero-5-volume-3-dezembro$\underline{2018}$.
} 


\section{HISTÓRIA \\ Apresentação ao dossiê "Futebol, biografias e memórias"}

Bernardo Buarque de Hollanda

Raphael Rajão Ribeiro

pensar a emergência do nacionalismo no contexto pós-colonial dos países do sudoeste asiático.

O segundo assunto destacado por Guedes na sua apreciação de conjunto relaciona-se às torcidas organizadas, cujo envolvimento com a pauta da opinião pública atinente à violência urbana vem demandando da Academia estudos de relativização dos estigmas, da naturalização de comportamentos desviantes e do etos associado a estes agrupamentos juvenis na contemporaneidade.

Tendo em vista os avanços reflexivos na exploração da identidade nacional e da violência no futebol, consideramos de modo alternativo um dossiê com foco futebolístico capaz de cobrir um ângulo novo do assunto e, ao mesmo tempo, de não deixar de incitar questões tradicionais e caras ao terreno da historiografia.

Nesse sentido, elegemos dois flancos de abrangência: a relação dual entre história e memória, sempre importante como suporte conceitual na elaboração teórica dos historiadores; e a biografia, dimensão de igual importância na reflexão em torno da escrita historiográfica, em função do que pressupõe para o entendimento da relação entre indivíduo, sociedade e temporalidade, ou, para usarmos os termos críticos de Bourdieu, para desconstruir sua "ilusão biográfica".

Ambos os temas sugeridos consistem em questões frequentes de interpelação, quer aos estudiosos do futebol tout court, quer aos historiadores que se dedicam a analisar as fronteiras de seu métier profissional com outras áreas. O dossiê Futebol, biografias e memórias mobiliza, pois, um ponto de partida metodológico para refletir sobre o estudo da prática deste esporte profissional, a saber, a escrita de sua história vis-à-vis a narrativa dos jornalistas esportivos.

O aquecimento do mercado editorial com livros sobre futebol, especialmente na conjuntura dos megaeventos esportivos, é uma das expressões mais candentes dos desafios de se pensar uma história científica desta modalidade esportiva, face a um volumoso material preexistente, com a capacidade de fornecer dados e informações abundantes, mas dotados de objetivos e métodos diversos daqueles almejados pelos historiadores profissionais. Assim, embora com objetos convergentes, os objetivos de 


\section{HISTÓRIA \\ Apresentação ao dossiê "Futebol, biografias e memórias"}

Bernardo Buarque de Hollanda

Raphael Rajão Ribeiro

cientistas sociais e jornalistas muitas vezes divergem quando se trata de procedimentos de pesquisa relacionados ao futebol.

Em artigo seminal sobre os usos do gênero biográfico na história e no jornalismo, Benito Bisso Schmidt (1997) detém-se na gama de aproximações e de afastamentos entre as duas áreas, mediadas pela literatura ou pelo que Walter Benjamin compreende como a "arte de narrar". Ao abordar a emergência da biografia na vida contemporânea, Bisso salienta, entre os jornalistas, o advento do new journalism nos Estados Unidos, em meados do século passado, bem como o modo pelo qual as biografias são exploradas, porquanto suscitam a curiosidade e despertam de sedução no imaginário coletivo em face da vida privada de personalidades e homens célebres.

Em contrapartida, os historiadores assistiram a uma retomada dos relatos biográficos desde fins dos anos 1970, quando a historiografia deixa de lado postulados estruturalistas e críticas ao positivismo da história oficial, também chamada dos grandes vultos, para apostar no potencial de abordagens históricas que podem, no limite, ajudar a reconstituir painéis históricos inteiros. O reconhecimento do papel do sujeito na história permite a recuperação das histórias de vida de anônimos, seja os egressos da cultura popular do Renascimento - como no caso do moleiro Menocchio de Carlo Ginzburg - seja os personagens saídos da cavalaria medieval - como no episódio do marechal Guillaume, enfocado por Georges Duby.

Não é o momento apropriado, nos limites de uma Apresentação, para aprofundar a longitude dessa discussão. Nosso intuito consiste apenas em sublinhar a pertinência do debate escolhido para esse dossiê, bem como sua relevância de fundo, na medida em que se trata de articular os estudos futebolísticos com a agenda de questões biográficas e memorialísticas com que a historiografia se depara de maneira cíclica.

Para este número, após o cumprimento das etapas constitutivas do "fazimento editorial", quais sejam, a divulgação da chamada, a submissão dos autores, o parecer por pares cegos, a retificação dos originais em atendimento às avaliações, o cumprimento dos prazos e a padronização final dos textos à guisa de publicação - o 


\section{HISTÓRIA \\ Apresentação ao dossiê "Futebol, biografias e memórias"}

Bernardo Buarque de Hollanda

Raphael Rajão Ribeiro

presente dossiê chegou à seleção de 8 artigos aprovados, somados a uma entrevista e a uma resenha.

Além de uma contribuição em espanhol, submetida por trio de pesquisadores uruguaios, observa-se o alcance nacional do dossiê, em termos de diversidade regional, institucional, disciplinar e de titulação dos autores cujos textos foram afinal aprovados. Haja vista que a maioria das biografias tende a enfocar futebolistas que se tornaram ídolos esportivos, o presente dossiê contempla análises de personagens históricos, como Pelé e Garrincha, chegando até os dias de hoje, com o caso de Neymar Jr.

Outro alvo tematizado no dossiê são os livros apologéticos que narram a saga dos clubes de futebol, via de regra escritos por aficionados e memorialistas. Estes, na linha dos antiquaristas, voltam-se para o passado das suas agremiações clubísticas, em busca de datas, anedotas, mitos de origem e feitos extraordinários protagonizados por figuras lendárias do seu panteão.

Ainda no quesito do memorialismo, o dossiê conta com uma contribuição que se debruça sobre a trajetória do torcedor-símbolo de um modesto clube de Pelotas, o Farroupilha. Neste trabalho, o argumento incide na construção da persona abnegada, cujos sacrifícios altruísticos em prol do time do coração exemplificariam o lídimo amor clubístico, à primeira vista autêntico e incondicional.

Dois outros artigos perscrutam as origens futebolísticas por meio dos espaços, um deles com foco no futebol de várzea paulistano, outro com respeito à introdução da prática nas praças públicas da cidade de Fortaleza. Aqui lança-se luz no caráter espacial do jogo, seguido por modificações bruscas desses mesmos espaços ao longo do século XX e no início do século XXI, relegando-as à condição de esquecimento.

Não obstante, tais artigos chamam ao mesmo tempo a atenção para a imbricação dos dois episódios com as abordagens contemporâneas que entendem a relação espaço-temporal na chave não somente dos documentos, mas também dos monumentos, com destaque para os lugares de memória a que se referia Pierre Nora.

Last but not least, o dossiê completa-se com a publicação de uma entrevista e de uma resenha, sendo ambas voltadas para as práticas e representações do futebol 


\section{HISTÓRIA \\ Apresentação ao dossiê "Futebol, biografias e memórias" \\ Bernardo Buarque de Hollanda \\ Raphael Rajão Ribeiro}

feminino no Brasil. Esta temática, não custa repetir, vem cada vez mais galvanizando pesquisadores interessados em revisitar a escrita da história deste esporte à luz dos estudos de gênero e das questões que se colocam para a mulher e para o corpo feminino na contemporaneidade.

Por fim, não podemos deixar de reiterar nosso agradecimento ao generoso convite de Kelen para a organização do dossiê que ora vem a público, após quase um ano de labor e de preparação.

\section{Referências bibliográficas}

CAMPOS, Priscila (et. al.). "Produção sobre futebol nas ciências humanas e sociais: um mapa a ser analisado. In: CORNELSEN, Élcio Loureiro; CAMPOS, Priscila; SILVA, Sílvio Ricardo da. Futebol: linguagens, artes, cultura e lazer. Rio de Janeiro: Jaguatirica, 2017.

GUEDES, Simoni. "Esporte, lazer e sociabilidade". In: DUARTE, Luiz Fernando Dias (Org.). Horizontes das ciências sociais no Brasil: antropologia. São Paulo: ANPOCS, 2010.

SCHIMDT, Benito Bisso. "Construindo biografias...historiadores e jornalistas: aproximações e afastamentos”. In: Estudos Históricos. Rio de Janeiro, n. 19, 1997, p. 3-21.

SPAGIARI, Enrico; MACHADO, Giancarlo; GIGLIO, Sérgio (Orgs.). Entre jogos e copas: reflexão de uma década esportiva. São Paulo: Intermeios/Fapesp, 2016. 